\title{
Age-age correlation for early selection of rubber tree genotypes in São Paulo State, Brazil
}

\author{
Paulo de Souza Gonçalves ${ }^{1}$, Nelson Bortoletto ${ }^{2}$, Átila Bento Beleti Cardinal ${ }^{3}$, \\ Lígia Regina Lima Gouvêa ${ }^{4}$, Reginaldo Brito da $\operatorname{Costa}^{5}$ and Mário Luiz Teixeira de Moraes ${ }^{6}$ \\ ${ }^{I}$ Instituto Agronômico de Campinas, Programa Seringueira, Campinas, SP, Brazil. \\ ${ }^{2}$ APTA Regional Noroeste Paulista, Votuporanga, SP, Brazil. \\ ${ }^{3}$ Instituto Agronômico de Campinas, Pós-graduação, Campinas, SP, Brazil. \\ ${ }^{4}$ Instituto Agronômico de Campinas, Bolsista CNPq, Campinas, SP, Brazil. \\ ${ }^{5}$ UCDB Programa de Desenvolvimento Local, Campo Grande, MS, Brazil. \\ ${ }^{6}$ Universidade Estadual Paulista 'Júlio de Mesquita Filho', Campus Ilha Solteira, São Paulo, SP, Brazil.
}

\begin{abstract}
In a field trial involving 68 rubber tree (Hevea spp.) clones calculation of genotypic correlation coefficients revealed significant age-age correlation from age 1 to 6 (immature period) for girth $A$ and for age 7 to 12 (mature period) for girth $B$ and for age 7 to 12 (production of latex) for yield. Rank correlation coefficients between all immature ages of girth (girth A), all ages of mature girth (girth B) and all annual rubber production (yield) were significant for the three traits, with the coefficients decreasing with increasing age. Selection of the sets of best 30,15, 10 and 5 clones from the available 68 clones at a given age was generally accompanied by a descending order of percentage success. It was suggested: (a) to have the best 30 clones of age 6 , select the set of best 36 clones at age 2, (b) to have the best 15 clones of age 6 , select the set of best 20 clones at age 3, (c) to have the best 5 clones of age 6 , select the set of best 8 clones at age 4 , and (d) to have the best 3 clones of age 6 , select the set of best 3 clones at age 5 . More than $80 \%$ of the targeted clones on girth $A$ or girth $B$ basis and more than $76.7 \%$ clones on yield basis were found to get selected at steps (a) through (d). For achieving early multiplication of the most productive clone for deployment, multiplication should be started with the best 36 (i.e. $60 \%$ ) clones selected at age 2 .
\end{abstract}

Key words: Hevea brasiliensis, early clonal multiplication, genetic correlation, rank correlation, evaluation of clones.

Received: June 15, 2004; Accepted: March 23, 2005.

\section{Introduction}

The major source of natural rubber is the rubber tree, Hevea brasiliensis (Willd. Adr. ex Juss.) Muell.-Arg. (family Euphorbiaceae), which is perennial and has na economically useful lifespan of ' $30-35$ years. Adult trees shed their leaves almost completely for 3-4 weeks each year in a process known as wintering, subsequent to which they undergo "flushing" and produce new flowers, leaves and shoots. Flowering in Hevea normally occurs once a year after leaf fall and is directly affected by climatic factors, Hevea species having traditionally been cultivated in humid equatorial regions subject to monsoons (Rao and Vijayakumar, 1992) and characterized by adequate rainfall distribution and small yearly fluctulations in temperature and humidity (Rao et al., 1993). In some countries to achieve self-

Send correpondence to Paulo de Souza Gonçalves. Instituto Agronômico de Campinas, Programa Seringueira, Caixa Postal 28, 13001-970 Campinas, SP, Brazil. E-mail: paulog@iac.sp.gov.br. sufficiency, attempts have been made to extend Hevea cultivation to marginal areas with varied climatic constraints, some areas being as far north as $29^{\circ}$ in India and China and south to $23^{\circ}$ in the Brazilian state of São Paulo (Pushparajah, 1983; Ortolani et al., 1998).

Rubber trees are grown for their latex from which is collected by tapping, coagulated and processed to form rubber, hence it is the dry rubber yield that determines the level of output. Girth is considered to be a measure of vigor and is also an economically important character because it determines the age at which a Hevea clone can be commercially exploited by tapping and is, therefore, important in shortening the uneconomic immature period of the clone. However, there are several high yielding clones whose girthing is depressed by tapping (Abraham, 1992) because this procedure is controlled wounding and as such stresses the tree and retards growth, especially if carried out when the trees are budding. 
In tree breeding, early selection has been shown to have three main advantages: increased overall selection intensity or a reduce in the amount of field-testing a shortened generation interval; and the fact that genetic information from early testing can be used to enhance selection efficiency maturity (Wu, 1998). Wu (1998) has developed a theoretical basis to study the effects of increased overall selection intesity and reduced field-testing but the most frequently cited advantage of early selection in tree breeding is shortened generation interval because this causes a reduction in the length of the breeding cycle (Nanson, 1970; Lambeth, 1980; McKeand, 1988; Adams et al., 1989; Adams and Atiken, 1992; Matheson et al., 1994). Shortening the breeding cycle of a tree through early selection can produce more genetic gains per unit time (year) if there is strong genetic correlation between early and mature traits.

Rubber is a forest tree crop and takes more than 25 years to complete a breeding cycle because of which genetic improvement of Hevea is normally a slow process, even for a single selection and breeding cycle. In Hevea breding there is usually a lapse of 3 years from pollination to field planting and since rubber trees generally require several years (often 6 or more) to reach tapping girth there is a wait of 7-9 years until tapping is started and then a 10-15 years period of tapping and clone evaluation.

Determining trends in age-age correlation is relatively simple for growth and yield traits, requiring only patience and repeated assessment. While there have been many reported age-age correlations for growth in conifers (e.g. Lambeth, 1980; McKeand, 1988; Riemenschneider, 1988; King and Burdon, 1991; Matheson et al., 1994) there are few for Hevea species (Gonçalves et al, 1988.)

The objective of the research described in the present paper was to use age-age correlations and selection efficiency estimates to study the potential of early selection of Hevea for forward breeding using data from a series of assessments of a Hevea spp. clone trial carried out in the northwest of the Brazilian state of São Paulo.

\section{Material and Methods}

In this study we used 55 Brazilian, 10 Malaysian and three Indonesia genotypes (clones) from a small-scale clone trial belonging to the Campinas Agronomic Institute (Instituto Agronômico de Campinas - IAC), Campinas, São Paulo state, Brazil) breeding program. The Brazilian clones were developed by the IAC breeding program while the Malaysian genotypes consisted of seven Rubber Research Institute of Malaysia (RRIM) clones and three clones belonging to the Prang Besar (PB) private rubber plantation. The Indonesian genotypes (clones) came from Proefstation voor Rubber (PR) in Sumatra. All the clones were budded onto established rootstock (Tjir 1 x Tjir 16) at the nursery. One-year-old rootstock seedlings raised in nurseries were used to budgraft clonal materials in December 1990, successful budgrafts being transplanted into polyethylene bags and the plantlets established in the field after the first flush of leaves developed.

The clones were grown at the Votuporanga Experimental Station $\left(20^{\circ} 25^{\prime} \mathrm{S}, 49^{\circ} 59^{\prime} \mathrm{W}\right.$, elevation $\left.450 \mathrm{~m}\right)$ in the nortwest of the Brazilian state of São Paulo. Mean monthly temperatures varied from 20 to $25^{\circ} \mathrm{C}$ and the average annual rainfall ranged from $1.087 \mathrm{~mm}$ to $1.537 \mathrm{~mm}$ and the winter drought varied from four to six dry months with an average water deficiency of $180 \mathrm{~mm}$. The trial was laid out in a randomized complete block design with three replicates using six trees replications per plot and 7 × $3 \mathrm{~m}$ spacing. Missing plants were replaced with spares during the first two years after planting to maintain plantation density but were not scored. One row of the commercial clone RRIM 600, acquired from a commercial nursery, was planted around the plot. Annual fertilization consisted of $400 \mathrm{~g}$ of 10-10-10 NPK formula per plant (Bataglia and Gonçalves, 2002).

Twelve months after planting the diameter of the stems of the plantlets were measured $0.5 \mathrm{~cm}$ above ground level using a slide caliper and this measurement converted to girth assuming that the stem was cylindrical. Immature girth (girth A) was measured at 2, 3, 4, 5 and 6 years and mature grith (girth B) at $8,9,10,11$ and 12 years. At the end of the sixth year all the trees with a girth of $45 \mathrm{~cm}$ or more were tapped for annual latex production $1.2 \mathrm{~m}$ above the highest point of the bud union using a half-spiral four-day tapping system (seven tappings per month) for 11 months per year. Yield was recorded on the days when normal tapping, which starts around 7:30 AM, was possible, the latex being collect in individual plastic cups for each tree and coagulated by adding $2 \%(\mathrm{v} / \mathrm{v})$ acetic acid solution, with stirring, to the cup once the latex flow had stopped. The coagulated rubber in each cup was made into a "biscuit" which was dried for about 30 days by hanging it on a wire tied to the tree from which it had been extracted. After dry, each rubber biscuit was weighed and the dry rubber content for each tree recorded. Attempts were made to record 12 girths measurements and six annual yields.

A combined three-factor cross classification analysis of variance (ANOVAR) was performed on the data using the statistical model:

$Y_{i j k}=\mu+g_{i}+a_{j}+b_{k}+(g a)_{i j}+(g b)_{i k}+(a b)_{j k}+(g a b)_{i j k}$,

where, $Y_{i j k}=$ observed value of the $i$ th genotype in the year in the $k$ th replication; $\mu=$ general mean; $g_{i}=$ fixed effect of the $i$ th genotype $(i=1,2, \mathrm{~g}, \mathrm{~g}=68) ; a_{j}=$ effects of the $j$ th year $(j=1,2, \mathrm{~s}, \mathrm{~s}=6) ; b_{k}=$ effect of the $k$ th randomized block $(k=1,2, \mathrm{~b}, \mathrm{~b}=3) ;(g a)_{i j}=$ interaction between $i$ th genotype with the $j$ th year; $(g b)_{i k}=$ interaction between $i$ th genotype with the $k$ th replication; $(g a b)_{i j k}=$ interaction between genotype, year and replication. It the assumed that the interactions $(a b)_{i j}$ and $(g b)_{i k}$ were not significant, these being included in the residual together with ( $g a b) i j k$. 
Data from more than three traits were used for computation of genotypic age-age correlation using the Selegen software (Resende and Oliveira, 1997). Values of genotypic correlation were computed among all traits and age combinations. Genotypic correlations were worked out according to Kempthorne (1966) as follows:

$$
r_{g(x y)}=\frac{\operatorname{COVg}_{(x y)}}{\sqrt{\sigma_{g x}^{2} \cdot \sigma_{g y}^{2}}},
$$

where $C O V g_{(x y)}=$ the genotypic covariance for traits $x$ and $y ; \sigma_{g x}^{2}=$ genotypic variance for trait $x ; \sigma_{g y}^{2}=$ genotypic variance for trait $y$.

For each trait, Spearman's rank correlation coefficient $\left(r_{s}\right)$ was computed between age 6 and younger ages. Rank 1 was assigned to the lowest value and rank 68 to the highest value within each age for a given trait. The significance of these correlations was tested using the Table XXV of Fisher (1941), for genotypic correlations for 5 and 1\% probability. The genotypic correlations were tested at the degrees of freedom of the error. Percent success in correctly selecting the best $5,10,15$ or 30 clones at age 2 and above was calculated using the ranks of clones method. Scatter plots between ranks at age 6 and at younger ages were plotted for each trait. Scatter plots of ranks for girth between age 2 and 3, age 3 and 4, and age 4 and 5 were also produced, showing the identification numbers of respective clones against the plotted points.

\section{Results}

All effects including the genotype versus years interaction were highly significant $(p<0.01)$ statistically in the overall analysis of variance for girth $\mathrm{A}$, girth $\mathrm{B}$ and yield (Table 1).

Significant positive genotypic correlation coefficients $\left(r_{g}\right)$ were observed for all the combinations of traits and ages (Table 2). The $r_{g}$ values were higher for traits of the same age group and as the difference increased $r_{g}$ usually decreased. The $r_{g}$ values within a trait varied from 0.3916 to 0.9916 for girth A, 0.5116 to 0.9517 for girth B and 0.3916 to 0.9612 for yield. The $r_{g}$ values between girth $\mathrm{A}$ and girth $\mathrm{B}$ were high, althoygh both girth values showed low $r_{g}$ values in relation to yield.

Similarly, significant of rank correlation coefficient $\left(r_{s}\right)$ values were observed between age 6 and younger ages for girth A, girth B and yield (Table 3 ). The values of $r_{s}$ with reference to age 6 ranged from 0.5498 (for age 1) to 0.9420 (for age 5) for girth $\mathrm{A}$, from 0.5114 (for age 1) to 0.9471 (for age 5) for girth B, and from 0.3451 (for age 1) to 0.8311 (for age 5) for yield. Since $r_{s}$ was significant for all age combinations, it shows that there were no drastic changes in the ranks of the different clones between age 1 and 6 .

Table 4 shows that selecting the best 30 clones at age 2 would lead to the best $69.93 \%$ of clones on a girth A basis (or $76.59 \%$ on a girth B or yield basis) being correctly selected at age 6 and the proportion increased to between $83.25 \%$ and $89.91 \%$ if selection was made at age 3 and $89.91 \%$ to $96.57 \%$ at age 4 . The success in correctly selecting the set of the best 15 clones at age 6 by selection at age 3 was $66.70 \%$ on a girth $\mathrm{A}$ basis and $80.04 \%$ on a girth $\mathrm{B}$ or yield basis, the success being much lower when the trees were selected at less than 3 years of age. The success in correct selection of the set of the best 5 clones at age 4 was $80 \%$ on a girth $\mathrm{A}$ or girth B basis and only $60 \%$ on a yield basis.

Figure 1 shows the scatter plot of ranks of clone means for girth A by plotting the ranks at age 6 along $\mathrm{X}$-axis and ranks at younger ages along the $\mathrm{Y}$-axis. With an increase in age along the $\mathrm{Y}$-axis, the plotted points tend to converge along the imaginary diagonal drawn from the origin. If the ranks on the $\mathrm{X}$ and $\mathrm{Y}$-axes belong to the same age, the plotted points would be axiomatically be on the diagonal. As the difference in age in the two axes increased, the values of $\mathrm{X}$ and $\mathrm{Y}$ fall more and more out of step, resulting in increased scattering of the points and lower $r_{s}$ values.

Of the best 34 girth A clones (ranking from 35 to 68 ) at age 6, 24 were also among the best 34 clones at age 2 while 27 clones were among the best 36 clones at this age. By selecting the best 34 girth A clones at age two we could select $76.7 \%$ of the best 34 clones at age 6 and this success rate could be increased to $90 \%$ if 38 age 2 clones were used. Similarly, by selecting the best 15 girth A clones at age 3 we

Table 1 - Analysis of variance for immature girth ages (girth A), girth mature ages (girth B) and rubber production (yield) for 68 Hevea genotypes (clones) grown in Votuporanga, São Paulo State, Brazil.

\begin{tabular}{lrccc}
\hline Sources of variation & d.f. & Girth A $(\mathrm{cm})$ & Girth B $(\mathrm{cm})$ & Yield $(\mathrm{g})$ \\
\hline Replications & 2 & 6.1755 & 27.3758 & 164.6510 \\
Genotypes & 67 & $138.7458^{* *}$ & $206.8648^{* *}$ & $2002.3679^{* *}$ \\
Years & 5 & $12642.7641^{* *}$ & $4747.0498^{* *}$ & $12670.7851^{* *}$ \\
Genotypes x years & 335 & $12.0233^{* *}$ & $8.6361 \mathrm{~ns}$ & $29.9479^{* *}$ \\
Residual & 815 & 3.8935 & 8.8062 & 65.70636 \\
Mean & & 21.82 & 56.98 & 40.71 \\
Coef. of variation $(\%)$ & & 9.02 & 5.20 & 19.91 \\
\hline
\end{tabular}

$* *$ significant for $\mathrm{p}<0.01$. 

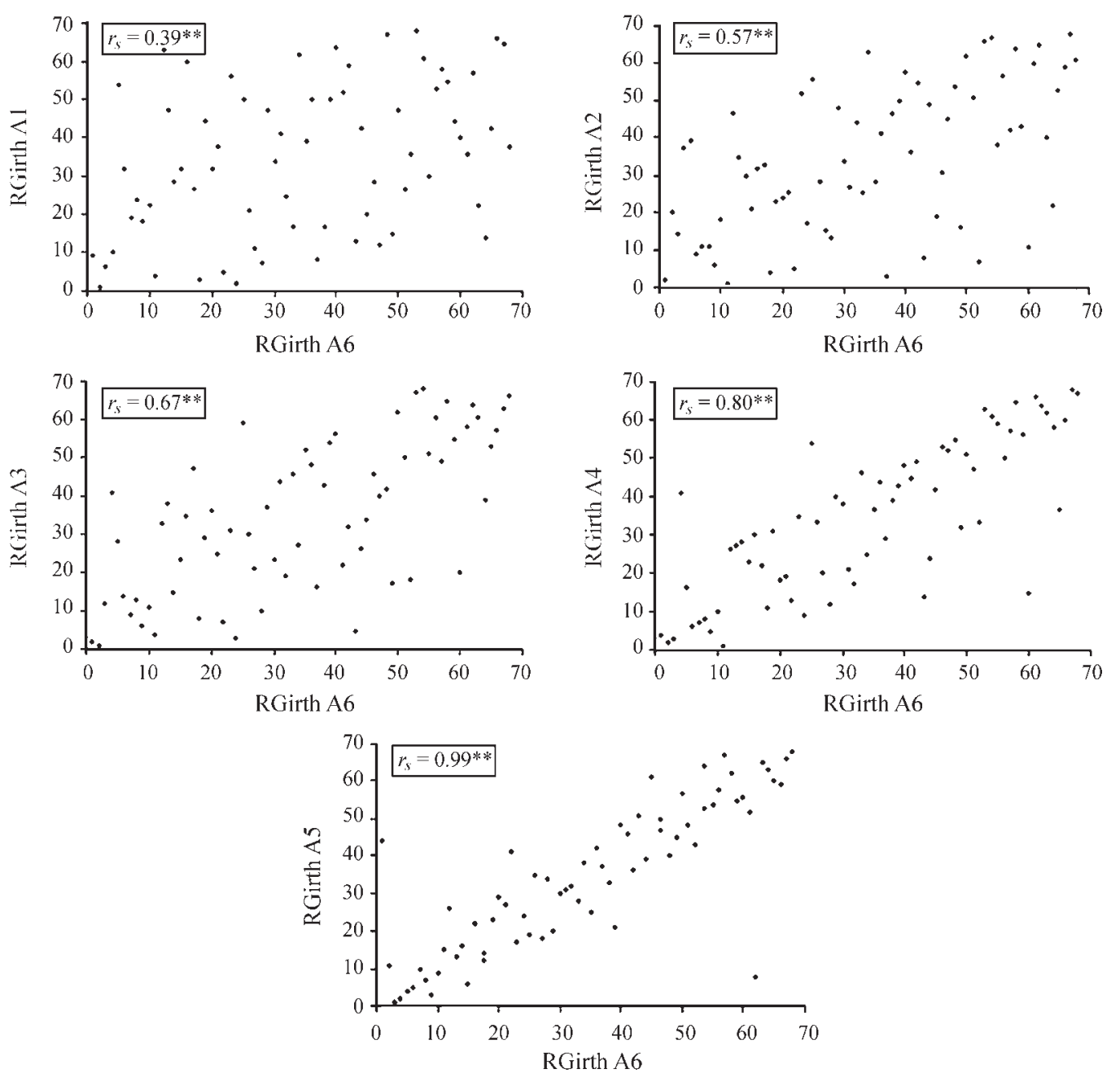

Figure 1 - Scatter plot ranks recorded at age six ranks at age 1 (i), 2 (ii), 3 (iii), 4 (iviv) and 5 (v) for mean girth A values of 68 clones. The rank of the girth A values at 1 year, 2 years, etc are indicated as Rgirth A1, Rgirth A2.

could select $80 \%$ of the set of the best 15 clones at age 6 and this success rate could be increased to $93.3 \%$ if 20 age 2 cloens were used. Selecting the best 5 girth A clones at age 4 meant that $60 \%$ of the set of the best 5 clones could be selected at age 6 and this could be increased to $100 \%$ if 8 clones were selected at age 4 (Figure 1). The scatter plots of girth B and yield (not shown) also showed a similar trend. Selection of the set of the 3 most productive clones at age 6 could be made with accuracy at age 5, although the ranks of the three clones changed among themselves during the sixth year.

Of the best 20 clones at age 3, the number of clones that simultaneously existed in the set of the best 36 clones at age 2 was 20 on a girth A basis [Figure 2(i)] and 19 each on a girth $\mathrm{B}$ or yield basis. The best 8 clones at age 4 invariably appeared in the set of the best 20 clones at age 3 for girth $\mathrm{A}$ (Figure 2 (ii)), girth B or yield. Each of the best 5 clones at ages 5 and 6 were among the best 8 clones at age 4 for girth A (Figure 2 (iii)), or girth B, while only 4 clones out of 5 top-ranking clones at age 6 could do so in respect of yield.

\section{Discussion}

The presence of significant clone versus site interaction indicates that genotypes perform differently between years for girth A, girth B and yield.

Existence of a strong, positive genotypic correlation (Table 2) as well as rank correlation (Table 3) between girth $\mathrm{A}$, girth $\mathrm{B}$ and yield suggests that selection of clones for superiority in respect of one of these traits would inevitably lead to selection of superior clones in respect to the other two traits as well. However, any decision on the selection of clones should preferably be taken on the basis of the girth $\mathrm{A}$ trait because vigor, represented by girth volume, is more closely related with girth A than with girth B or yield only. We also suggest that for early evaluations girth A should be used in preference to secondary characters such as height, number of laticiferous vessel rings, etc.

It was not possible to predict with any fair degree of success as to which clone would occupy a particular rank at 

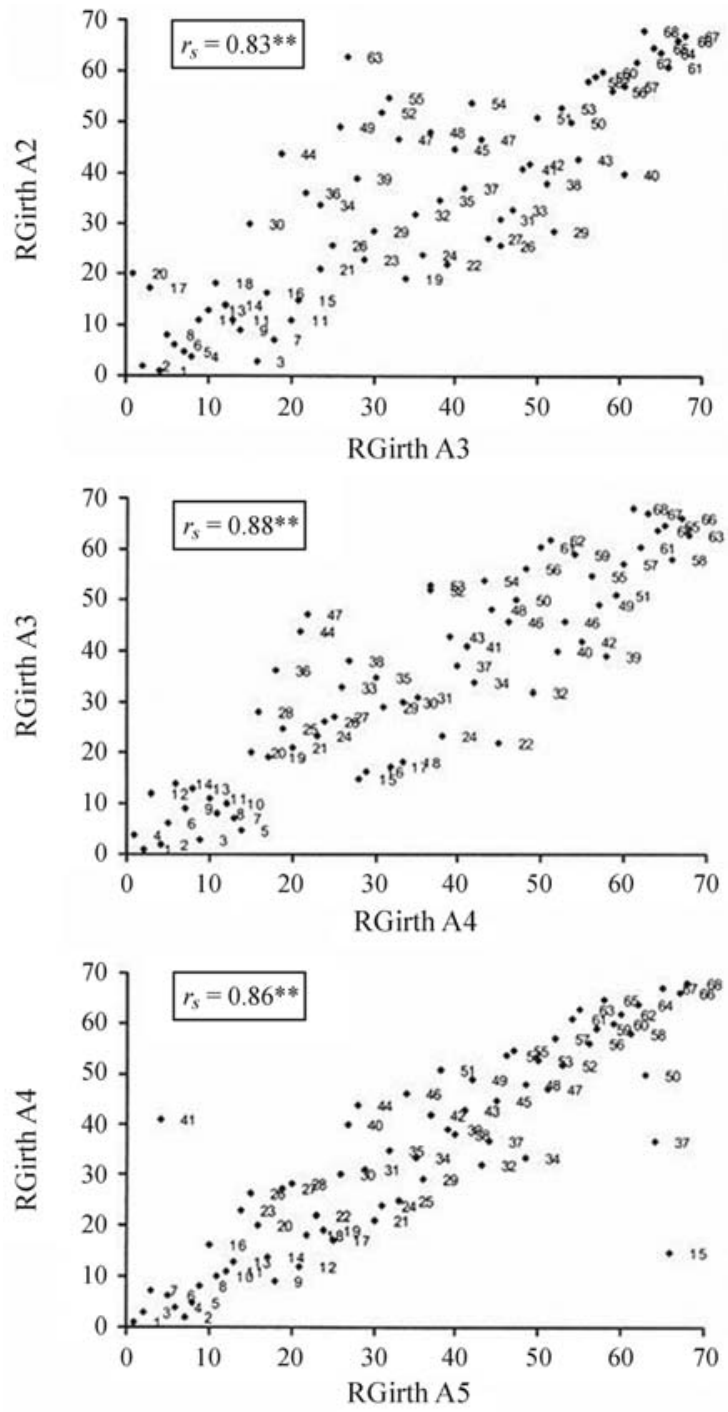

Figure 2 - Scatter plot of ranks for Girth A recorded between (i) age 2 and 3 , (ii) age 3, (ii) age 3 and 4 (iii) age 4 and 5. The clone identification numbers are printed above the corresponding points in the plot.

panel opening age (Figure 1). At younger ages, a realistic attempt can be made to determine only the set of the best $n$ clones $(n>1)$ at panel opening age, without allocating the $n$ ranks of panel opening age to individual clones. Therefore, exchange of ranks between clones within the selected set of clones was not viewed as a waste of selection effort during this study.

Gottardi et al., (1995) reported that the ranking in girth A among 11 Hevea clones did not vary much after 3 years up to 7 years of age. The mean data for each clone showed good genotypic correlation for girth between age 7 and young ages. The coefficient increased with increasing age suggesting that early selection was possible. Gonçalves et al., (1998) suggested that selection of fastest growing

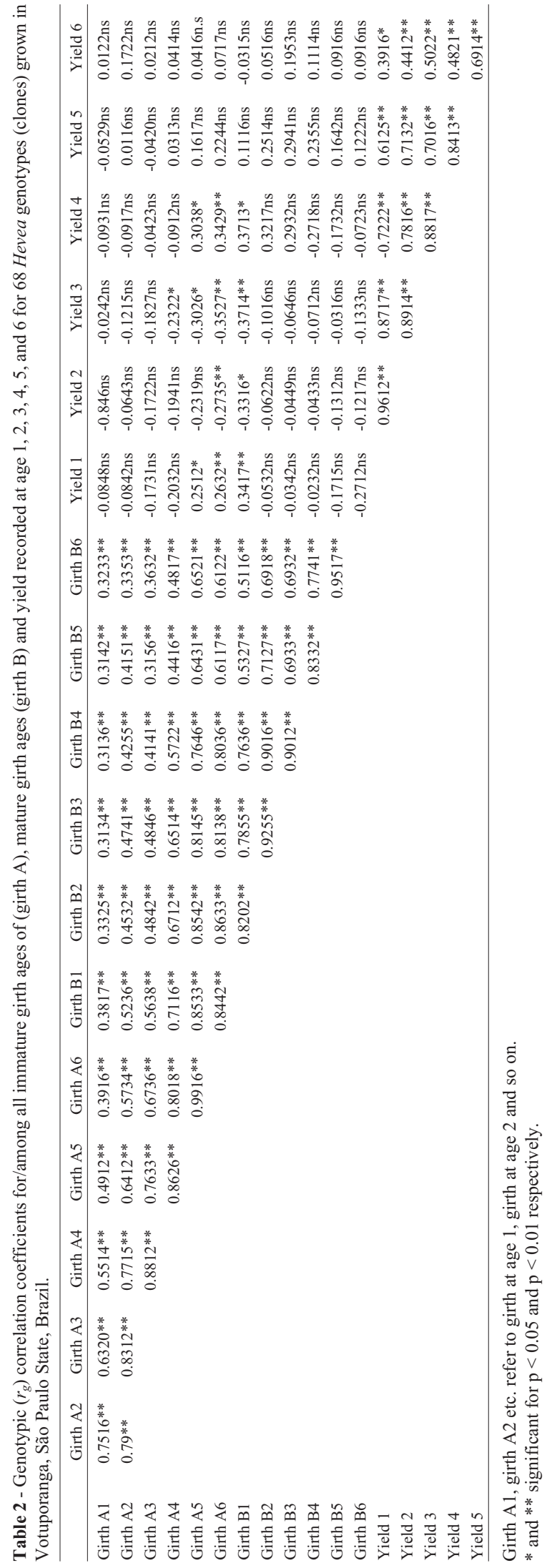


Table 3 - Values of Spearman's rank correlation coefficient $\left(r_{s}\right)$ between age 6 and younger ages for immature girth age (girth (A), mature girth age (girth B) and rubber production (yield) for 25 Hevea genotypes (clones) grown in Votuporanga, São Paulo State, Brazil.

\begin{tabular}{llllll}
\hline Trait & \multicolumn{5}{c}{ Age combination (years) } \\
\cline { 2 - 6 } & 1 and 6 & 2 and 6 & 3 and 6 & 4 and 6 & 5 and 6 \\
\hline Girth A & 0.5498 & 0.6773 & 0.7723 & 0.8005 & 0.9420 \\
Girth B & 0.5114 & 0.5685 & 0.8320 & 0.9046 & 0.9471 \\
Yield & 0.3451 & 0.5988 & 0.5185 & 0.6556 & 0.8311 \\
\hline
\end{tabular}

All values in table are significant at $\mathrm{p}<0.01$.

Hevea clones could be done on a girth basis after 24 months.

Our study shows that in São Paulo it may be unwise to select Hevea clones at age 1, although the 2 to 4 -year growth data can be used differentially in the selection process. Selection of the sets of the best $30,15,10$ and 5 clones from the available 68 clones at a given age was generally accompanied by a descending order of percentage success (Table 4). Thus, for a given level of percentage success in selection, the set of clones to be selected at a relatively young age needs to be large, while selection of a small set needs a higher selection age. Therefore, it is suggested that: a) to have the best 30 (i.e. $44 \%$ of the available germplasm) clones at age 6 select the set of the best $36(53 \%)$ clones at age $2 ; b)$ to have the best $15(22 \%)$ clones at age 6 select the set of the best $20(29.41 \%)$ clones at age 3 ; c) to have the best $5(7.35 \%)$ clones at age 6 select the set of the best 8 $(11.76 \%)$ clones at age 4 ; and d) to have the best $3(4.4 \%)$ clones at age 6 just select the set of the best $3(4.41 \%)$ clones at age 5 . More than $80 \%$ of the clones targeted on a girth A or yield basis, and more than $76,7 \%$ clones targeted on a girth $\mathrm{B}$ basis, were found to be correctly identified during steps (a) to (d). Nevertheles, the 5 highest-ranking age 6 clones (viz. clones with identification numbers 68, 67, 66, 65 and 64) on a girth A (Figure 1 and 2) or girth B basis were found to be invariably present in the sets of clones selected at (a), (b) and (c).

One is often faced with the task of making early selection of clones on the basis of a field test to give interim recommendation about the choice of clone for further multi-location testing (large-scale trials). The age of early selection needs to be sufficently long to effect a reasonable level of selection accuracy. After making early selection, vegetative multiplication of the selected clones is started and it is continued for many years in order to build the budwood stock nursery which is large enough to supply buds to all rubber producers on a sustained basis. To shorten the time involved in this two-stage process of $(i)$ selecting the most promissing clones, followed by (ii) multiplying their germplasm, an alternative approach involving concurrent short-listing and multiplication of clones is suggested. According to this approach, early selection of the best $60 \%$ of clones should be done at age 2 of the field trial
Table 4 - Extent of success in correctly selecting a set of 5, 10, 15 or 30 best clones for age 6 (girth) and age 6 (yield) by making selection at age 2 , $3,4,5$ or 6 respectively.

\begin{tabular}{|c|c|c|c|c|c|c|}
\hline \multirow{2}{*}{$\begin{array}{l}\operatorname{Tr} \\
\text { (a) }\end{array}$} & \multirow{2}{*}{$\begin{array}{c}\text { Sa } \\
\text { Years } \\
\text { (b) }\end{array}$} & \multicolumn{2}{|c|}{$\mathrm{Ct}$} & \multicolumn{2}{|c|}{ Cs } & \multirow{2}{*}{$\begin{array}{c}\mathrm{Pe} \\
\% \\
(\mathrm{~g})^{3}\end{array}$} \\
\hline & & $\begin{array}{l}\mathrm{N} \\
\text { (c) }\end{array}$ & $\begin{array}{c}\% \\
\text { (d) }{ }^{1}\end{array}$ & $\begin{array}{l}\mathrm{N} \\
\text { (e) }\end{array}$ & $\begin{array}{c}\% \\
(f)^{2}\end{array}$ & \\
\hline Girth A & 2 & 5 & 7.35 & 3 & 4.41 & 60.00 \\
\hline Girth A & 3 & 5 & 7.35 & 4 & 5.88 & 80.00 \\
\hline Girth A & 4 & 5 & 7.35 & 4 & 5.88 & 80.00 \\
\hline Girth A & 5 & 5 & 7.35 & 4 & 5.88 & 80.00 \\
\hline Girth A & 2 & 10 & 14.70 & 5 & 7.35 & 50.00 \\
\hline Girth A & 3 & 10 & 14.70 & 8 & 11.76 & 80.00 \\
\hline Girth A & 4 & 10 & 14.70 & 8 & 11.76 & 80.00 \\
\hline Girth A & 5 & 10 & 14.70 & 10 & 14.70 & 80.00 \\
\hline Girth A & 2 & 15 & 22.06 & 7 & 10.29 & 46.67 \\
\hline Girth A & 3 & 15 & 22.06 & 10 & 14.70 & 66.70 \\
\hline Girth A & 4 & 15 & 22.06 & 12 & 17.64 & 80.04 \\
\hline Girth A & 5 & 15 & 22.06 & 12 & 17.64 & 80.04 \\
\hline Girth A & 2 & 30 & 44.12 & 21 & 30.87 & 69.93 \\
\hline Girth A & 3 & 30 & 44.12 & 25 & 36.75 & 83.25 \\
\hline Girth A & 4 & 30 & 44.12 & 27 & 39.69 & 89.91 \\
\hline Girth A & 5 & 30 & 44.12 & 28 & 41.16 & 93.24 \\
\hline Girth B & 2 & 5 & 7.35 & 3 & 4.41 & 60.00 \\
\hline Girth B & 3 & 5 & 7.35 & 3 & 4.41 & 60.00 \\
\hline Girth B & 4 & 5 & 7.35 & 4 & 5.88 & 80.00 \\
\hline Girth B & 5 & 5 & 7.35 & 4 & 5.88 & 80.00 \\
\hline Girth B & 2 & 10 & 14.70 & 7 & 10.29 & 70.00 \\
\hline Girth B & 3 & 10 & 14.70 & 6 & 8.82 & 60.00 \\
\hline Girth B & 4 & 10 & 14.70 & 7 & 10.29 & 70.00 \\
\hline Girth B & 5 & 10 & 14.70 & 9 & 13.23 & 90.00 \\
\hline Girth B & 2 & 15 & 22.06 & 10 & 14.70 & 66.70 \\
\hline Girth B & 3 & 15 & 22.06 & 12 & 17.64 & 80.04 \\
\hline Girth B & 4 & 15 & 22.06 & 12 & 17.64 & 80.04 \\
\hline Girth B & 5 & 15 & 22.06 & 13 & 19.11 & 86.71 \\
\hline Girth B & 2 & 30 & 44.12 & 23 & 33.81 & 76.59 \\
\hline Girth B & 3 & 30 & 44.12 & 25 & 36.75 & 83.25 \\
\hline Girth B & 4 & 30 & 44.12 & 29 & 42.63 & 96.57 \\
\hline Girth B & 5 & 30 & 44.12 & 30 & 44.10 & 100.00 \\
\hline Yield & 2 & 5 & 7.35 & 3 & 4.41 & 60.00 \\
\hline Yield & 3 & 5 & 7.35 & 2 & 2.94 & 40.00 \\
\hline Yield & 4 & 5 & 7.35 & 3 & 4.41 & 60.00 \\
\hline Yield & 5 & 5 & 7.35 & 4 & 5.88 & 80.00 \\
\hline Yield & 2 & 10 & 14.70 & 5 & 7.35 & 50.00 \\
\hline Yield & 3 & 10 & 14.70 & 8 & 11.76 & 80.00 \\
\hline Yield & 4 & 10 & 14.70 & 8 & 11.76 & 80.00 \\
\hline Yield & 5 & 10 & 14.70 & 10 & 14.70 & 100.00 \\
\hline Yield & 2 & 15 & 22.06 & 7 & 10.29 & 66.70 \\
\hline Yield & 3 & 15 & 22.06 & 12 & 17.64 & 80.04 \\
\hline Yield & 4 & 15 & 22.06 & 12 & 17.64 & 80.04 \\
\hline Yield & 5 & 15 & 22.06 & 14 & 20.58 & 96.38 \\
\hline Yield & 2 & 30 & 44.12 & 23 & 33.81 & 76.59 \\
\hline Yield & 3 & 30 & 44.12 & 27 & 39.69 & 89.91 \\
\hline Yield & 4 & 30 & 44.12 & 27 & 39.69 & 89.91 \\
\hline Yield & 5 & 30 & 44.12 & 28 & 41.16 & 93.33 \\
\hline
\end{tabular}

${ }^{1}(\mathrm{~d})=(\mathrm{c}) \times 100 / 68 ;{ }^{2}(\mathrm{f})=(\mathrm{e}) \times 100 / 68$ and ${ }^{3}(\mathrm{~g})=(\mathrm{e}) \times 100 /(\mathrm{c})$.

Tr: Trait for selection of clones. Sa: Selection age. Ct: Clones targeted for selection at selection age. Cs: Clones successfully selected at selection age with the aim of selection for age. Per: Per cent success of selection at selection age. N: Number. \%: \% of 68 . 
and their vegetative multiplication should be immediately started in the nursery. Short-listing of the best 33\% (of the original number of clones under test) clones should be done from within the above set of clones select at age 3 on the basis of (a) age 3 growth data in field trial and (b) grafting and survival performance of buds during the previous year in nursery. Propagation of the rejected clones should be stopped by uprooting and eliminating the rejected clones (roguing). This process of the simultaneous roguing of clones on the basis of current evaluation and the vegetative propagation of select clones can be continued in the subsequent years until the desired selection intensity and number of clones (ramets) are archieved, the best $5 \%$ of clones being shot-listed at age 5 .

Early selection might result in some bias against clones which grow relatively slow in the initial stage but catch up with others at the later stages. However, Figure 1 and Table 2 suggest that such clones would be very few, and, in fact, such clones would lag behind others if planted in intimate mixture with other clones at high densities. Since the objective of a Hevea improvement program is to maximize gains per unit time it is undesirable to delay making interim recommendation about choice of clones and starting their vegetative multiplication on the basis of early evaluation just because sporadic clones would be disfavored. Final recommendation on the choice of clones for later deployment in plantations and for serving as parents for the next generation of Hevea improvement can be done at year 4 because in São Paulo Hevea normally does not flower before this age.

\section{Conclusions}

Early selection of Hevea clones for tapping panel opening at age of 6 years can be done effectively at age 4 . Selection at age 2 is relatively less accurate but it results in early propagation of selected clones for further testing or deployment. To combine the advantages of these two early selection ages we suggest a differential selection strategy, i.e. the best $60 \%$ of clones of the original set should be selected at age $2,33 \%$ at age $3,13 \%$ at age 4 and $5 \%$ at age 5 . The sets of clones to be selected at age 3 and later should be contained in the sets selected in the perceding years. Multiplication of the selected clones should be started at the end of the second year of the field trial and continued in successive years. Selection at age 2 should be done on the basis of growth, preferably vigor (girth A) in the field trial.

\section{Acknowledgments}

The authors thank Fundação de Amparo a Pesquisa do Estado de São Paulo (FAPESP), for supporting this research. LRLG and PSG are recipeints of CNPq fellowships. $\mathrm{ABBC}$ is recipient of a FAPESP fellowship.

\section{References}

Abraham PD (1992) Tapping of Hevea brasiliensis. In: Sethuraj, JMR and Mathew, NM (eds) Rubber: Biology, Cultivation and Technology, 12, Elsevier Science Publishers, Amsterdam, pp 263-296.

Adams WT and Aitken S (1982) Pacific Northewest tree Improvement Research Cooperative Annual Report 1990-91. For Res Lab, Oregan State.

Bataglia OC and Gonçalves P de S (2002) Tecnologia da adubação da seringueira. Informativo Apabor 9:3-4.

Fisher RA (1941) Statistical Methods for Research Workers. Oliver and Boyd, Edinburgh, 316 pp.

Gonçalves P de S, Bortoletto N, Fonseca F da S, Bataglia OC and Ortolani AA (1998) Early selection for growth vigour in rubber tree genotypes in northwestern São Paulo State (Brazil). Genet Mol Biol 21:515-521.

Gottardi MVC, Gonçalves P de S, Cardoso M and Mente EM (1995) Correlações genotípicas e fenotípicas entre caracteres de seringueiras adultas. Cientifica 23:53-64.

Kempthorne O (1966) An Introduction to Genetic Statistics. John Wiley \& Sons, New York, 273 pp.

King JN and Burdon RD (1991) Time trends in inheritance and projected efficiencies of early in a large 17-year old progeny test of Pinus radiata. Can J For Res 21:1200-1207.

Lambeth CC (1980) Juvenile-mature correlations in Pinaceae and implications for early selection. For Sci 26:571-580.

Matheson A, Spencer DJ and Magnussen D (1994) Optimum age for selection in Pinus radiata using basal area under bark for age:age correlations. Silvae Gen 43:352-357.

McKeand SE (1988) Optimum age for family selection for growth in genetic test of loblolly pine. For Sci 34:400-411.

Nanson A (1970) Juvenile and correlated trait selection and its effect on selection programs. In: Proc. 2nd Meeting of Working Group on Quantitative Genetics IUFRO, Louisina, pp 17-25.

Ortolani AA, Sentelhas PC, Camargo MBP, Pezzopane Jem and Gonçalves P de S (1998) Agrometeorogical model for seasonal rubber tree yields. Indian J Nat Res 11:8-14.

Pushparajah E (1983) Problems and potentials for establishing Hevea under difficult environmental conditions. The Planter 59:242-251.

Rao PS, Jayarathnam K and Sethuraj MR (1993) An index to assess areas hydrotermally suitable for rubber cultivation. Indian J Nat Rub Res 6:80-91.

Rao OS and Vijayakumar KR (1992) Climatic requirements. In: Sethuraj MR and Mathew NM (eds) Natural Rubber: Biology, Cultivation and Technology. Elsevier, Amsterdam pp 200-219.

Resende MDV de and Oliveira EB (1997) Sistema "Selegen" seleção genética computadorizada para melhoramento de espécies perenes. Pesq Agrop Bras 32:931-939.

Riemenschneider DE (1988) Heritability, age-age correlations and inferences regarding juvenile selection in Jack Pine. For Sci 34:1076-1082.

Wu HX (1998) Study of early selection in tree breeding: I, advantage of early selection through increase of selection intensity and reduction of field test size. Silvae Genet 47:146-155. Associate Editor: Everaldo Gonçalves de Barros 